\title{
Smoking Treatment in Enhancing Banana Ripening and its Effects on Physical and Biochemical Attributes of Ambul Banana (Musa acuminata, AAB)
}

\author{
S.D.T. Maduwanthi and R.A.U.J. Marapana*
}

\section{ABSTRACT}

Smoking is a traditional practice used in enhancing the ripening process of banana. This study was conducted to analyze the effects of smoking treatment on different physical and biochemical parameters of Ambul banana (Musa acuminata, AAB). Bananas were screened by peel colour and fruit firmness to obtain samples at similar maturity stage. A sample was treated with smoke and stored at $20{ }^{\circ} \mathrm{C}$ and $80-85 \%$ relative humidity and the control sample was allowed to ripe naturally under the same conditions. Physical (peel colour, firmness) and biochemical parameters (moisture \%, pulp pH, TSS, titratable acidity, total sugar, total starch, organic acid profile, sugar profile, aroma profile) were tested at fully yellow stage (stage 6). Results revealed that smoking treatment can reduce the quality of banana by reducing its peel yellowness $\left(a^{*}\right)$ significantly at stage 6 and making black scars on peel. Further fruit firmness, moisture \% in peel and pulp $\mathrm{pH}$ were significantly $(p<0.05)$ affected by smoking. Total sugar showed nearly a twofold decrease in treated fruits $(10.26 \mathrm{~g} / 100 \mathrm{~g})$

Department of Food Science and Technology, University of Sri Jayewardenepura, Nugegoda, Sri Lanka

*umarapana@sci.sjp.ac.lk. http://orcid.org/0000-0001-7759-559X

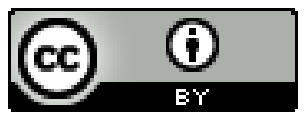

This article is published under the terms of the Creative Commons Attribution 4.0 International License. which permits unrestricted use, distribution and reproduction in any medium provided the original author and source are credited. while there was no appreciable difference in starch content. Fructose, glucose, malic acid, citric acid and oxalic acid were found in considerably lower levels in treated samples than in non-treated. Sucrose was completely unavailable in treated banana flesh. Smoked banana reported a poor aroma profile with few numbers of aroma compounds (19) where some esters such as ethyl acetate, butyl acetate, butyl pentanoate, 3-methylbutyl 2methylbutanoate, 2-methylpropylhexanoate, 2-methylpropyl acetate, 3-methylbutyl hexanoate and $[(E)$-hex-4-enyl] butanoate were not found.

Keywords: Ambul banana, Aroma volatiles, Induced ripening, Organic acids, Sugars

\section{INTRODUCTION}

Banana is the term used to represent many cultivars or species under genus Musa. It is known as one of the most popular fruits in the world. It has been ranked as the fourth most important food crop in the world (Maureen et al. 2016). There are two main types of banana; dessert types which are eaten raw and plantains which are eaten in cooked form. Annually 130 million tons of banana are being produced across the world while $50 \%$ of this production is consumed in the cooked form (Salunkhe and Kadam, 1995). Banana is one of the most important fruit crops in Sri Lanka as well. Annual banana production in Sri Lanka is around $62549 \mathrm{t}$. It is reported that 
there are 55 cultivars available in Sri Lanka where the most popular species are Ambul (Musaacuminata, AAB), Seeni (Musaacuminata, ABB), Kolikuttu (Silk, AAB) and Anamalu (Gross Michel, AAA).

Banana fruit is made with a peel and an edible pulp. Banana is rich in nutritional profile. Levels of nutrients vary with the type of cultivar and the maturity stage. Typically, the energy provided by banana (dessert type) lies between 80-120 $\mathrm{kcal} / 100 \mathrm{~g}$. Ripe banana contains $1-2 \%$ starch and 70-80\% free sugars including sucrose, fructose and glucose. Banana contains a very low amount $(0.3 \mathrm{~g} / 100 \mathrm{~g})$ of fat (Chandler, 1995; Marriott and Palmer, 1980). It is also rich with minerals such as phosphorous, sodium, potassium, calcium, magnesium, iron, copper, zinc, and manganese. Further it contains vitamin A, B6 and vitamin C. Banana is rich with bioactive compounds such as phenolics, flavonoids, carotenoids and biogenic amines (Singh et al. 2016).

In natural conditions, banana ripes slowly, leading to high weight loss, desiccation, uneven maturity levels and fails to develop good colour and aroma (Subbaiah et al. 2013). Therefore, to meet consumer expectations bananas are harvested when green but mature, and artificially ripened using ripening agents (Sogo-Temi et al. 2014). The ripening agents include artificial agents such as ethylene gas, ethephon, ethrel and calcium carbide. In developing countries inexpensive traditional and biological methods such as smoking, keeping with hay and banana leaves are practiced.

Smoking is popular in Sri Lanka as a traditional practice used to instigate ripening of banana which is still being used in some regions of the country. In traditional practice, green bananas are laid in a pit, covered with leaves and smoke is directed in to the pit for several hours It is believed that unsaturated compounds such as acetylene and ethylene present in the smoke enhance the ripening process. (Maduwanthi and Marapana, 2019a). As well increased temperature in the smoke accelerates the de-greening of the peel (Ranaweera et al. 2020).

Many studies have been done to analyze the effect of artificial ripening on physicochemical properties and sensory properties of banana. Many of them have revealed that artificial ripening can significantly affect biochemical and sensory attributes of banana (Kulkarni et al. 2011; Lustre et al. 1976; Sogo-Temi et al. 2014; Hakim et al. 2012; Maduwanthi and Marapana, 2019b). This study was done to analyze the effect of smoking on different physical and biochemical properties of Ambul banana (Musa acuminata, AAB).

\section{MATERIAL AND METHODS}

\section{Plant Material}

Ambul banana was procured from an orchard in Dankotuwa, Sri Lanka. Green mature bananas were tested for their peel 
colour and firmness using a Chroma meter (Lovibond LC 100, China) and a texture analyzer (CT3 Brookfield USA). Bananas which showed significantly similar $(p<0.05)$ levels of peel colour and firmness were taken for the analysis.

\section{Chemicals}

Standards of malic acid, oxalic acid, citric acid, tartaric acid, fructose, glucose, sucrose, maltose and ascorbic acid were obtained from Sigma, USA. All the other reagents and chemicals were analytical grade.

\section{Smoke Treatment}

Banana samples were kept in a smoking chamber covered with Bilimbi (Averrhoa bilimbi) leaves and exposed to wood smoke for 20 minutes. Then the samples were kept in a closed chamber under $20{ }^{\circ} \mathrm{C}$ and $80-85 \%$ relative humidity $(\mathrm{RH})$ until fruits become fully ripe.

Control samples were kept in a closed chamber under $20{ }^{\circ} \mathrm{C}$ and $80-85 \%$ $\mathrm{RH}$ until fruits become fully ripe.

\section{General Analysis}

The peel colour was measured using a Chroma meter (Lovibond LC 100, China) according to the $\mathrm{L}^{*} \mathrm{a}^{*} \mathrm{~b}^{*}$ colour scale with six replicate measurements. Texture analyzer (CT3, Brookfield USA) was used to measure the firmness of banana fruit. The test was done with TA44 probe,
$1 \mathrm{~mm} / \mathrm{s}$ test speed at $5 \mathrm{~mm}$ distance using $5 \mathrm{~g}$ trigger load.

Moisture content was analyzed using AOAC 925.10 method in banana peel and flesh. A solution was prepared by homogenizing the flesh with distilled water at 1:3 (w/w) ratio. The solution was used to measure TSS (Total Soluble Solids), pH and titratableacdity \% (TA\%). TSS of the solution was measured using digital refractometer (ATAGO PAL-1, Japan). The $\mathrm{pH}$ of the solution was measured using $\mathrm{pH}$ meter (Consort, C6010). TA\% of the banana pulp was determined by a titration according to Hossain et al. (2014). Above solution was titrated with $0.1 \mathrm{~N} \mathrm{NaOH}$ in the presence of phenolphthalein. TA\% was calculated using equation 1 and expressed as $\%$ of malic acid.

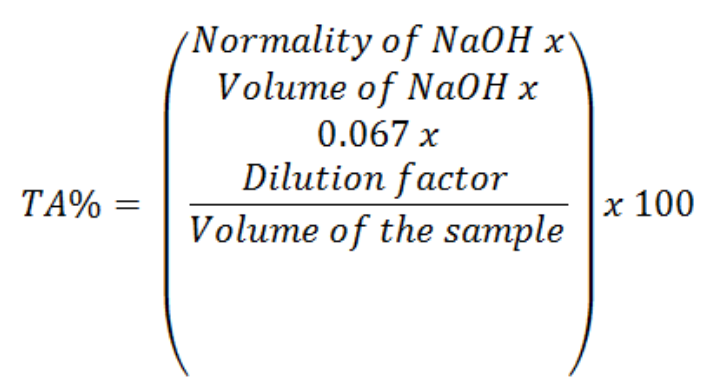

(Eq. 1)

\section{Total Sugar Analysis}

Total sugar analysis was done according to Hossain et al. 2014. Exactly $2 \mathrm{~g}$ of banana flesh was homogenized well and boiled with $20 \mathrm{ml}$ of $80 \%$ ethanol for 10 minutes. Further, extraction was done twice with $80 \%$ hot ethanol. Then the solution was filtered through a filter paper (Whatman 41). The extract was evaporated to dryness 
in a water bath and the residue was dissolved in $100 \mathrm{ml}$ of distilled water. Aliquot of $1 \mathrm{ml}$ of the prepared extract was mixed with $4 \mathrm{ml}$ of $0.2 \%$ Anthrone reagent (Sigma, Switzerland). Then the mixture was heated in a boiling water bath for 10 min and allowed to cool. The absorbance was measured at $680 \mathrm{~nm}$ using a spectrophotometer (SHIMADZU,UVmini1240). Total sugar was calculated using a standard curve prepared with five different concentrations of glucose standard (Supelco, Germany).

\section{Total Starch Analysis}

Total starch was analyzed according to the method described by Rose et al. (1991). Exactly $0.5 \mathrm{~g}$ of banana flesh was crushed with $80 \%$ hot ethanol twice to remove sugars. Extract was centrifuged at 6000 rpm for 10 minutes. The residue was dried in a water bath. Then $5 \mathrm{ml}$ of distilled water and $6.5 \mathrm{ml}$ of perchloric acid were added. The sample was mixed well and kept at $0^{\circ} \mathrm{C}$ for 20 minutes. Then the sample was centrifuged and the supernatant was separated. Then it was diluted up to $100 \mathrm{ml}$ with distilled water. Exactly $1 \mathrm{ml}$ of the extract was mixed with $4 \mathrm{ml}$ of $0.2 \%$ anthrone reagent (Sigma, Switzerland) and incubated in a boiling water bath for 10 minutes. After cooling, the absorbance was measured at $680 \mathrm{~nm}$ using a spectrophotometer (SHIMADZU, UVmini-1240). The amount of glucose present in the extracts was determined from the standard curve prepared. Starch content was calculated using the equation 2.

$$
\text { Starch }=\text { Glucose } \times 0.9 \quad \text { (Eq. 2) }
$$

\section{Organic Acid Analysis}

Malic acid, oxalic acid, tartaric acid and citric acid in banana flesh at fully yellow stage were analyzed by following the method described by Maduwanthi and Marapana, 2019b. Exactly, $5 \mathrm{~g}$ of banana flesh was homogenized with $10 \mathrm{ml}$ of deionized water. Then the mixture was centrifuged at $6000 \mathrm{rpm}$ for 10 minutes. The supernatant was filtered through 0.45 $\mu \mathrm{m}$ filters and filled in to $1.5 \mathrm{ml}$ sample vials. The organic acids were separated in the HPLC system (Agilent-1260-Infinity, Germany) using C18 column (Agilent Eclipse Plus C18, $5 \mu \mathrm{m} 4.6$ x $250 \mathrm{~mm}$ ) and UV detector. A mixture of Dipotassium Hydrogen Phosphate buffered at $\mathrm{pH} 2.6$ with orthophosphoric acid and $100 \%$ Methanol in the ratio 97:3 (v/v) was used as the mobile phase. For the quantification, external standards of malic acid, oxalic acid, tartaric acid and citric acid (Sigma, USA) were used.

\section{Sugar Analysis}

Sucrose, glucose, fructose and maltose in banana flesh at fully yellow stage were analyzed under this analysis. The procedure was developed and optimized based on Ma et al. (2014) with a few modifications. Five grams of fruit flesh was homogenized with $10 \mathrm{ml}$ of deionized water and centrifuged at $6000 \mathrm{rpm}$ for 10 minutes. The supernatant was filtered through $0.45 \mu \mathrm{m}$ filters and filled into 1.5 
$\mathrm{ml}$ sample vials. HPLC analysis was carried out using the Agilent-1260-Infinity HPLC system (Agilent, Germany) equipped with Refractive Index (RI) detector and Zorbax NH2 (4.6 mm x 250 $\mathrm{mm}, 5 \mu \mathrm{m}$, Agilent USA) analytical column. The mobile phase consisted of the ratio of 70: $30 \mathrm{v} / \mathrm{v}$ acetonitrile: water. External standards of sucrose, maltose, fructose and glucose (Sigma, USA) were used for the quantifications.

\section{Aroma Profile Analysis}

Solid Phase Micro Extraction (SPME) technique was used to analyze aroma profile of banana at fully yellow stage. The method was developed based on the method given in Bugaud and Alter (2016) with some modifications. Five grams of banana flesh was homogenized with $5 \mathrm{ml}$ of distilled water. Exactly, $1 \mathrm{~g}$ from the above mixture was transferred into a $20 \mathrm{ml}$ sample vial and it was heated at $60{ }^{\circ} \mathrm{C}$ for $10 \mathrm{~min}$ in a water bath. SPME fiber (Supelco, 50/30 $\mu \mathrm{m}$ divinylbenzene/ Carboxen on polydimethylsiloxane on a 2 $\mathrm{cm}$ stable flex fiber) was exposed into the headspace of the sample for $10 \mathrm{~min}$ at 60
${ }^{\circ} \mathrm{C}$. Volatile compounds were separated and identified using the GC-MS system under the conditions stated in Table 1.

The reference mass spectra (NIST 08) was used to identify the compounds. Relative Abundance \% (RA\%) of each aroma compound was calculated using the following equation 3 .

$$
R A \%=\frac{\text { Area of the peak }}{\text { Total sum of areas of all peaks }} \times 100 \%
$$

(Eq. 3)

\section{Vitamin C Analysis}

Vitamin $\mathrm{C}$ analysis was done based on the method given by Kapur et al. (2012) with few modifications. Five grams of banana flesh were homogenized with $25 \mathrm{ml}$ of metaphosphoric acid - acetic acid solution and diluted up to $50 \mathrm{ml}$ with metaphosphoric acid - acetic acid solution. Then the mixture was centrifuged at 6000 $\mathrm{rpm}$ for 15 minutes. Four $\mathrm{ml}$ of the supernatant was mixed with $230 \mu \mathrm{l}$ of $3 \%$ bromine, $130 \mu \mathrm{l}$ of $10 \%$ thiourea solution and $1 \mathrm{ml}$ of $2,4 \mathrm{DNPH}$ solution.

Table 1. Operational conditions of GC-MS used for aroma analysis

\begin{tabular}{ll}
\hline GC system & Agilent 7890A coupled with 5975C Mass Spectrophotometer \\
Column & DB-225MS (Agilent) capillary column $(30 \mathrm{~m}$ x $250 \mu \mathrm{m} \times 0.25 \mu \mathrm{m})$ \\
Carrier gas & Helium \\
Gas flow rate & $1 \mathrm{ml} / \mathrm{min}$ \\
Temperature & Started at $40{ }^{\circ} \mathrm{C}, 2^{\circ} \mathrm{C} / \mathrm{min}$ to $70^{\circ} \mathrm{C}$, held at $70^{\circ} \mathrm{C}$ for $5 \mathrm{~min}$, up to $170{ }^{\circ} \mathrm{C}$ \\
program & by $5^{\circ} \mathrm{C} / \mathrm{min}$, then $50^{\circ} \mathrm{C} / \mathrm{min}$ up to $220^{\circ} \mathrm{C}$ and finally maintained at $220^{\circ} \mathrm{C}$ \\
& for $5 \mathrm{~min}$ \\
Run time & $51 \mathrm{~min}$ \\
\hline
\end{tabular}


Then the solutions were kept in a water bath at $37{ }^{\circ} \mathrm{C}$ for 3 hours. The samples were cooled in ice for 30 minutes and $5 \mathrm{ml}$ $\begin{array}{llllll}\text { chilled } & 85 & \% & \mathrm{H}_{2} \mathrm{SO}_{4} & \text { was added. }\end{array}$ Absorbance was read at $521 \mathrm{~nm}$ in the UVVIS spectrophotometer (SHIMADZU, UV mini- 1240). The standard curve prepared with different concentrations of Vitamin $\mathrm{C}$ standard (Supelco, Germany) was used for the quantification.

\section{Statistical Analysis}

Data obtained were analyzed using twosample t-test and Mann-Whitney $U$ test where appropriate using MINITAB 17. Anderson-Darling test was used to test the normality of data. All the tests were done under $95 \%$ confidence level.

\section{RESULTS AND DISCUSSION}

When considering the efficiency of smoke treatment, banana treated with smoke was ripen at $6^{\text {th }}$ day while it took 8 days for the natural ripening process. Table 2 shows change in the ripening stage determined according to the Von Leosecke ripening scale (Von Loesecke, 1950).

Table 2. Ripening stage with time
However, black scars on peel were observed at stage 6 on the peel of smoked banana. A similar observation was noticed by Adane et al. (2015) where banana treated with kerosene smoke exhibited off ripening black scars on peel giving lower sensory quality.

Peel colour is the most important ripening index in banana fruit. In $\mathrm{L}^{*} \mathrm{a}^{*} \mathrm{~b}^{*}$ colour scale $\mathrm{L}^{*}$ represents lightness of the peel while $\mathrm{a}^{*}$ and $\mathrm{b}^{*}$ represent "Redness Vs Greenness" and "Yellowness Vs Blueness" respectively. Figure 1 shows change in $\mathrm{L}^{*}, \mathrm{a}^{*}, \mathrm{~b}^{*}$ and $\mathrm{C}^{*}$ in banana peel with time during the period of ripening.

Lightness $\left(\mathrm{L}^{*}\right)$ of the peel increased from $53.92 \pm 2.27$ at stage 1 to $67.48 \pm 0.95$ at stage 6 in natural ripening. $L^{*}$ at stage 6 in smoked banana was reported as $70.75 \pm 1.43$ which was significantly high $(\mathrm{p}<0.05)$ compared to the corresponding value in natural ripening. When the fruit ripens gradually greenness reduces.

Accordingly, $\mathrm{a}^{*}$ increased from negative values to positive values. Green banana (Stage 1) showed $-11.93 \pm 0.71 \mathrm{a}^{*}$ value. It was

\begin{tabular}{lllllllllll}
\hline \multirow{2}{*}{ Treatment } & \multicolumn{10}{c}{ No of days } \\
\cline { 2 - 11 } & $\mathbf{1}$ & $\mathbf{2}$ & $\mathbf{3}$ & $\mathbf{4}$ & $\mathbf{5}$ & $\mathbf{6}$ & $\mathbf{7}$ & $\mathbf{8}$ & $\mathbf{9}$ & $\mathbf{1 0}$ \\
\hline Natural ripening & S1 & S2 & S3 & S3 & S3 & S3 & S4 & S6 & S6 & S7 \\
Smoke & S1 & S2 & S3 & S3 & S5 & S6 & S6 & S7 & & \\
\hline S1- Green, S2-Colour Break, S3- More green than yellow, S4- More yellow than green, \\
S5- Yellow with green tip, S6-Fully yellow, S7- Over ripe.
\end{tabular}


increased up to $2.6 \pm 0.66$ in natural ripening and $5.13 \pm 1.59$ in smoked bananas.Yellowness $\left(b^{*}\right)$ increased during ripening up to stage 6 in natural ripening. It decreased when fruit reached to stage 7 . However, in smoked banana yellowness at stage 6 was $46.80 \pm 0.80$ which was lower than yellowness of naturally ripened samples at stage 6.

Reduction in flesh firmness during banana ripening is mainly associated with cell pectin degradation and the conversion of starch into sugar (Khanbarad et al. 2012). The firmness of banana flesh was $414.85 \pm 53.45 \mathrm{~g}$ at the unripe stage and it showed a continuous reduction during the ripening process (Figure 2).
Flesh firmness at stage 6 in naturally ripened samples was $42.6 \pm 2.9 \mathrm{~g}$ while it was $31.3 \pm 4.8 \mathrm{~g}$ in smoked banana. It indicates that smoke treatment can significantly reduce flesh firmness at fully yellow stage which can lead to poor quality in banana.

When considering moisture \% in peel, smoked banana showed reduced content of moisture. However, moisture content in flesh did not show any appreciable difference between treated and non-treated samples (Table 3).
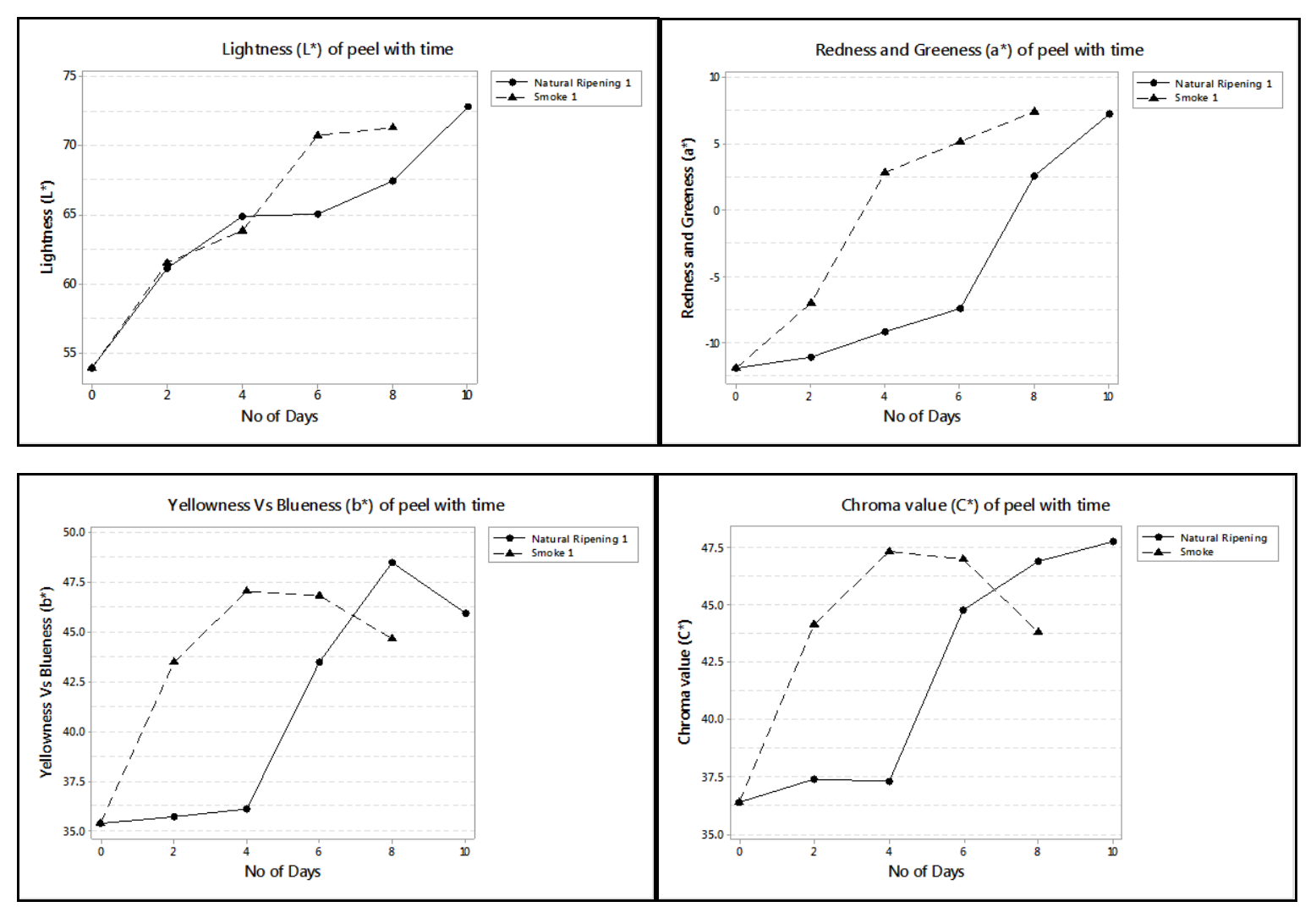

Figure 1. Variation of $\mathrm{L}^{*}, \mathrm{a}^{*}, \mathrm{~b}^{*}$ and $\mathrm{C}^{*}$ in banana peel during ripening of banana 


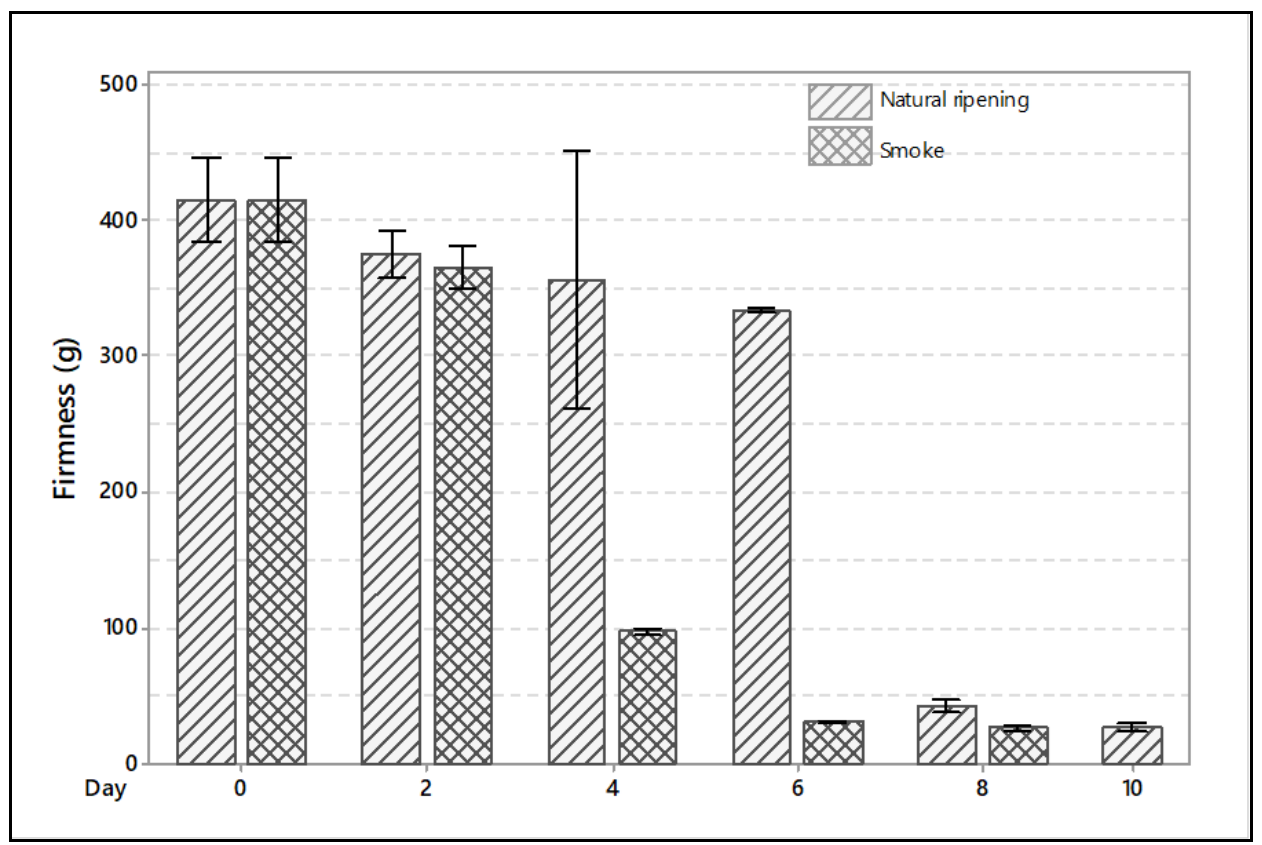

Each bar represents mean $\pm S D$ of 6 independent samples

Figure 2. Variation of firmness in banana flesh during ripening in treated and non-treated banana.

Further, TA\% and TSS in banana flesh was not significantly affected by smoke treatment. Anyhow, it was noted that $\mathrm{pH}$ in flesh was considerably low in smoked banana indicating that smoking can reduce the sensory quality of banana.During ripening sugar content increases as starch converts to sugar.

Table 3. Some of the physicochemical parameters of banana treated with smoke against nontreated banana at stage 6

\begin{tabular}{lll}
\hline \multirow{2}{*}{\multicolumn{1}{c}{ Parameter }} & \multicolumn{2}{c}{ Fully yellow stage (Stage 6) } \\
\cline { 2 - 3 } & \multicolumn{1}{c}{ Natural Ripening } & \multicolumn{1}{c}{ Smoke } \\
\hline Moisture \% in peel & $86.0 \pm 0.9 \%^{\mathrm{a}}$ & $83.6 \pm 0.5 \%^{\mathrm{b}}$ \\
Moisture \% in flesh & $74.0 \pm 0.5 \%^{\mathrm{a}}$ & $73.8 \pm 0.9 \%^{\mathrm{a}}$ \\
Titratable Acidity \% & $0.104 \pm 0.069 \%^{\mathrm{a}}$ & $0.114 \pm 0.009 \%^{\mathrm{a}}$ \\
$\mathrm{pH}$ in flesh & $5.130 \pm 0.140^{\mathrm{a}}$ & $4.265 \pm 0.064^{\mathrm{b}}$ \\
TSS in flesh $\left({ }^{0} \mathrm{Brix}\right)$ & $4.9 \pm 0.0^{\mathrm{a}}$ & $5.0 \pm 0.1^{\mathrm{a}}$ \\
Total sugar $(\mathrm{g} / 100 \mathrm{~g})$ & $19.91 \pm 0.74^{\mathrm{a}}$ & $10.26 \pm 0.09^{\mathrm{b}}$ \\
Total starch $(\mathrm{g} / 100 \mathrm{~g})$ & $1.22 \pm 0.19^{\mathrm{a}}$ & $1.12 \pm 0.02^{\mathrm{a}}$ \\
Vitamin C $(\mathrm{mg} / 100 \mathrm{~g} \mathrm{FW)}$ & $30.15 \pm 0.81^{\mathrm{a}}$ & $7.34 \pm 0.39^{\mathrm{b}}$ \\
\hline
\end{tabular}

The table consists of mean $\pm S D$ of 4 independent samples. Means bearing different superscripts, row-wise differ significantly at $95 \%$ confidence level. 
Total sugar content in naturally ripened banana at stage 6 was $19.91 \pm 0.74$ $\mathrm{g} / 100 \mathrm{~g}$. Total sugar at stage 6 was significantly low in smoked banana as it was nearly a twofold reduction. This may be due to the incompleteness of the sugar metabolism in smoked samples due to early activation of climacteric rise. Starch remaining at stage 6 was similar in both treated and non-treated samples.

As represented in Table 3, vitamin C is considerably affected by smoke treatment as there was $7.34 \pm 0.39 \mathrm{mg} / 100 \mathrm{~g}$ of vitamin $\mathrm{C}$ in treated banana samples. However, the content of vitamin $\mathrm{C}$ was $30.15 \pm 0.81 \mathrm{mg} / 100 \mathrm{~g}$ in naturally ripened banana samples.

Figure 3 shows the variations of organic acids; citric, malic, oxalic and tartaric acid flesh of banana treated with smoke. Organic acids play a major role in flavour of banana as well as in many fruits. Many researchers have reported that malic acid is the major acid in ripe banana (Kheng et al. 2012).

A similar observation was noted under this analysis as malic acid was the most abundant acid in ripe banana flesh which was naturally ripened. According to the data obtained, citric and malic acids were the most abundant acids in both treated and non-treated banana at stage 6 . Smoked banana contained considerably less amount of malic acid (265.74 \pm 0.93 $\mathrm{mg} / 100 \mathrm{~g}$ of Fresh Weight/FW) comparing to that of naturally ripened samples. Further, citric acid and oxalic acid contents

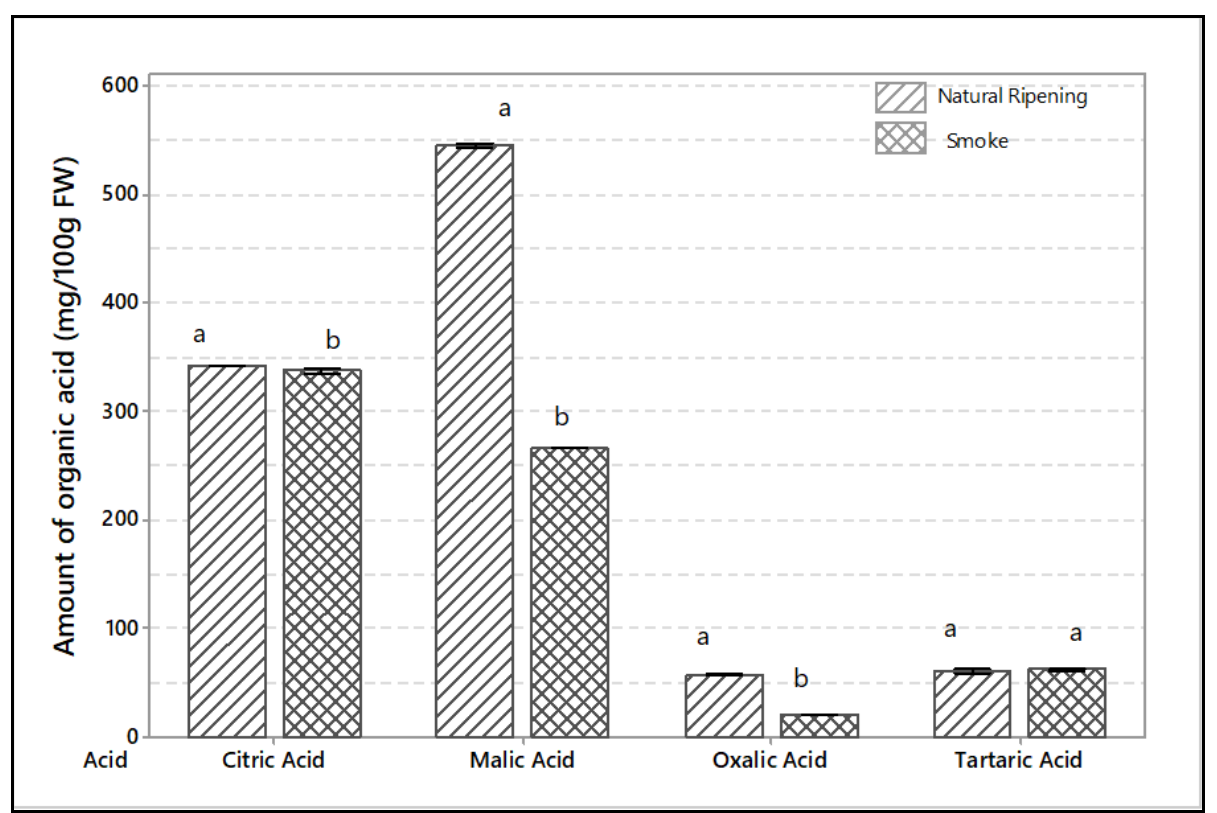

Each bar represents mean \pm SD of 3 independent samples. Bars bearing same letter within a group are not significantly different at $95 \%$ confidence level

Figure 3. Organic acids in banana flesh at stage 6 in treated and non-treated banana 
were also significantly low in smoke treated samples. There was no significant difference in tartaric acid content between treated and non-treated banana.

During ripening, starch degrades and sugar accumulates in flesh. Under this analysis sucrose, fructose, glucose and maltose were analyzed. However, maltose was not present in banana flesh at any ripening stage. Fructose and glucose were the most available free sugars in banana flesh at the fully yellow stage (Figure 4). Fructose and glucose contents in banana flesh under natural ripening were 7.72 and $7.36 \mathrm{~g} / 100 \mathrm{~g}$ of $\mathrm{FW}$ respectively. The amounts of fructose and glucose in smoked banana reported as 6.64 and $6.43 \mathrm{~g} / 100 \mathrm{~g}$ of FW respectively which were significantly lower than that of naturally ripened samples. Sucrose was present only in naturally ripened samples where the content was very less $(1.11 \mathrm{~g} / 100 \mathrm{~g}$ of FW). Sucrose was not detected in smoked fruits.

Based on the results of aroma profile analysis, 27 aroma compounds were identified in naturally ripened banana whereas only 19 compounds were detected in smoked samples. Some esters such as ethyl acetate, butyl acetate, butyl pentanoate, 3-methylbutyl 2methylbutanoate, 2-methylpropyl hexanoate, 2-methylpropyl acetate, 3methylbutyl hexanoate and $[(E)$-hex-4enyl] butanoate were not detected in smoked banana samples.

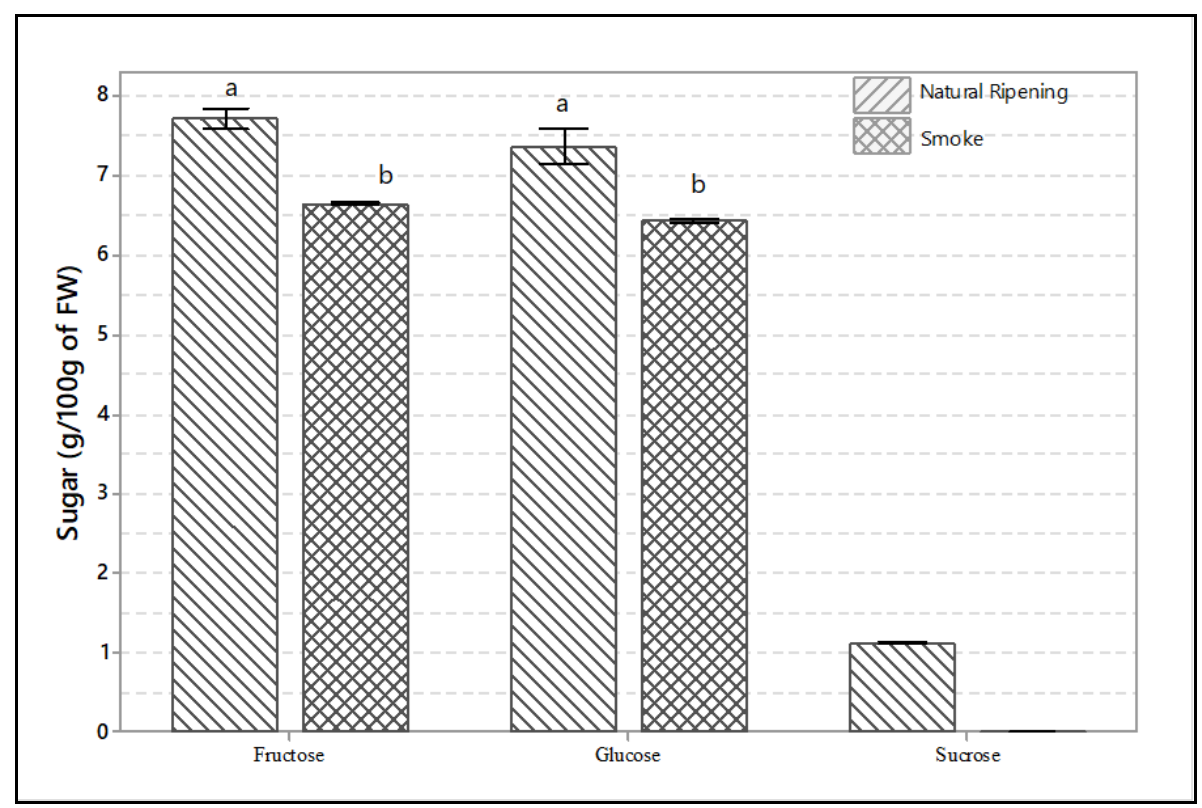

Each bar represents mean \pm SD of 3 independent samples. Bars bearing same letter within a group are not significantly different at $95 \%$ confidence level.

Figure 4. Sugars in banana flesh at stage 6 in treated and non-treated banana 
Considering the numbers of esters present in the aroma profile (Figure 5), 17 aroma compounds were detected in naturally ripened samples where 13 esters were available in smoked samples. Sonmezdag et al. (2014) reported that artificially ripened banana has a poor aroma profile compared to naturally ripened banana. The number of alcohols, aldehydes and benzenic derivatives was also less in number in smoked samples. Some esters namely heptan-2-yl butanoate, 2-methylpropyl 2-methylbut-2-enoate and hexyl butanoate were only found in smoked banana.

\section{CONCLUSION}

Smoke treatment can enhance banana ripening successfully as smoked banana samples were fully yellow within the first 6 days while the natural process took 8 days. Black scars on peel were noticed in smoked samples at stage 6. As per peel colour measurements, yellowness $\left(a^{*}\right)$ was significantly low in banana treated with smoke. Flesh firmness was also affected by smoking treatment indicating that smoked banana is less hard than naturally ripened samples. Moisture \% in peel and $\mathrm{pH}$ in flesh was considerably low in treated samples whereas TA\%, TSS in flesh and pulp moisture \% did not show any significant difference between the samples. There was a huge reduction in total sugar in treated banana flesh. Contents of individual free sugars such as fructose and glucose were reported to be low in smoked samples. Sucrose was found only in naturally ripened samples.

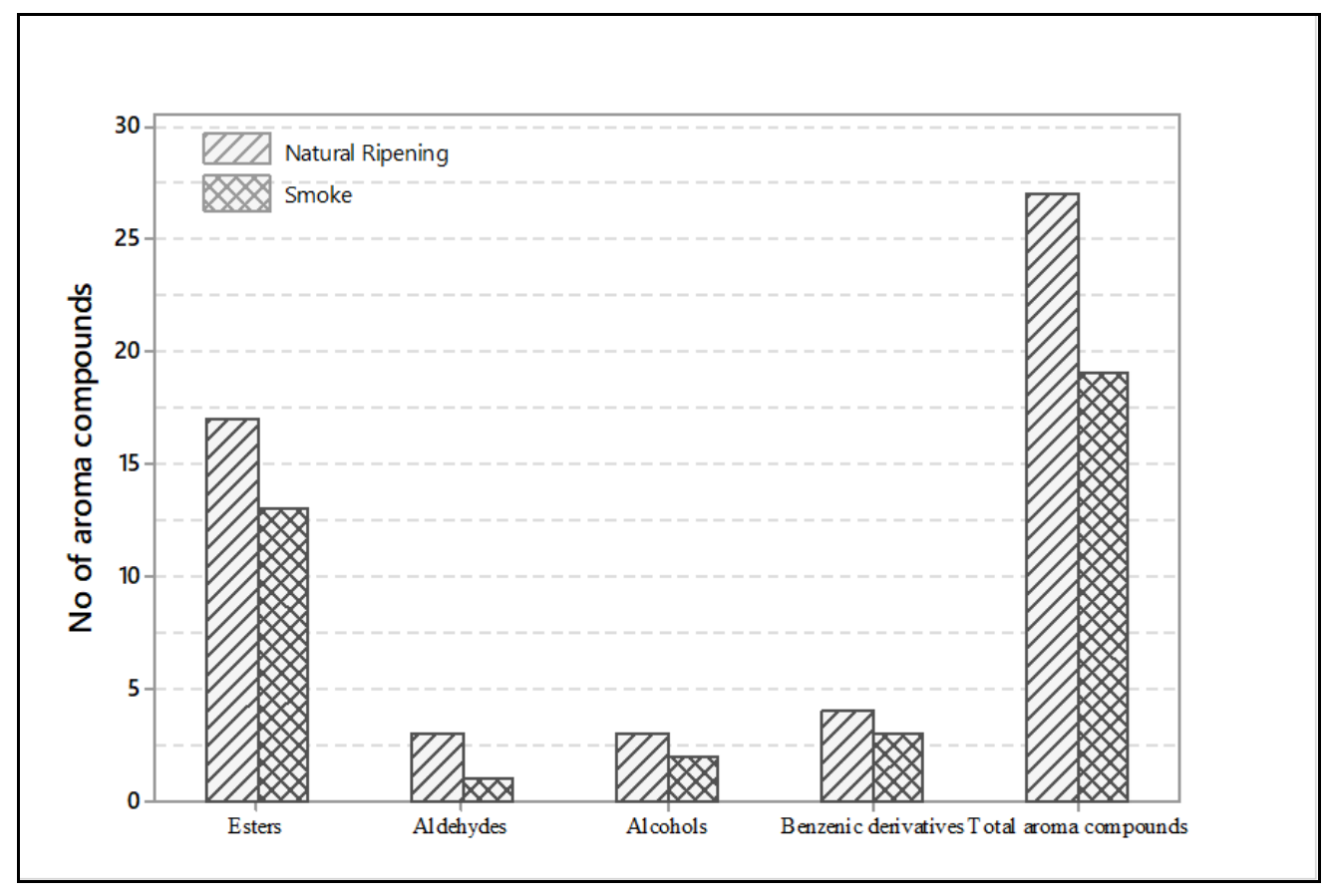

Figure 5. Number of esters, aldehydes, alcohols and benzenic derivatives in the aroma profile of treated and non-treated banana. 
Malic acid was the major acid available in ripe banana flesh under natural ripening. Anyhow, the content of malic acid was considerably affected by smoke treatment. Most abundant organic acid in smoked banana flesh was citric acid. There was no considerable variation in starch content between two samples. However, smoked banana reported a nearly fourfold reduction in vitamin $\mathrm{C}$ content. Aroma profile of smoked banana was reported to be poor having less number of total aroma compounds and less number of esters. Some of the esters were completely unavailable in the aroma of smoked samples.

\section{ACKNOWLEDGMENT}

Authors acknowledge University Research Grants, University of Sri Jayewardenepura, Sri Lanka for funding this study under the grant numbers of ASP/01/RE/SCI/2016/12 and 2018/40.

\section{REFERENCES}

Adane, Z. W., Ibrahim, A. M., Yohannes, D. B. and Welde-Meskel, T. A. (2015). Effect of traditional kerosene smoking and ethrel on ripening, shelf life and quality of Cavendish banana (Musa sp.). African Journal of Agricultural Research, 10(50): 4570-4583.

Bugaud, C. and Alter, P. (2016). Volatile and non-volatile compounds as odour and aroma predictors in dessert banana (Musa spp.). Postharvest Biology and Technology, 112: 14-23.

Chandler, S. (1995). The nutritional value of bananas. In: Gowen S. (Eds.),
Bananas and Plantains. World Crop Series. Springer, Dordrecht.

Hakim, M. A., Huq, A. O., Alam, M. A., Khatib, A., Saha, B. K., Haque, K. F., and Zaidul, I. S. M. (2012). Role of health hazardous ethephone in nutritive values of selected pineapple, banana and tomato. Journal of Food, Agriculture \& Environment, 10(2): 247-251.

Hossain, M., Rana, M., Kimura, Y. and Roslan, H. A. (2014). Changes in biochemical characteristics and activities of ripening associated enzymes in mango fruit during the storage at different temperatures. BioMedical Research International, 2014.

Kapur, A., Hasković, A., ČopraJanićijević, A., Klepo, L., Topčagić, A., Tahirović, I. and Sofić, E. (2012). Spectrophotometric analysis of total ascorbic acid content in various fruits and vegetables. Bulletin of the Chemists and Technologists of Bosnia and Herzegovina, 38(4): 39-42.

Khanbarad, S. C., Thorat, I. D., Mohapatra, D., Sutar, R. F. and Joshi, D. C. (2012). Effect of temperature and period of storage on physical, biochemical and textural properties of banana during ripening. Journal of Dairying Foods \& Home Sciences, 31(3): 212-215.

Kheng, T. Y., Ding, P. and Abdul Rahman, N. A. (2012). Determination of optimum harvest maturity and physico-chemical quality of Rastali banana (Musa AAB Rastali) during fruit ripening. Journal of the Science of Food and Agriculture, 92(1): 171-176.

Kulkarni, S. G., Kudachikar, V. B. and Prakash, M. K. (2011). Studies on physico-chemical changes during artificial ripening of banana (Musa sp) variety 'Robusta'. Journal of Food 
Science and Technology, 48(6): 730734.

Lustre, A. O., Soriano, M. S., Morga, N. S., Balagot, A. H. and Tunac, M. M. (1976). Physico-chemical changes in 'Saba' bananas during normal and acetylene-induced ripening. Food Chemistry, 1(2): 125-137.

Ma, C., Sun, Z., Chen, C., Zhang, L. and Zhu, S. (2014). Simultaneous separation and determination of fructose, sorbitol, glucose and sucrose in fruits by HPLC-ELSD. Food Chemistry, 145: 784-788.

Maduwanthi, S. D. T. and Marapana, R. A. U. J. (2019)a. Induced ripening agents and their effect on fruit quality of banana. International Journal of Food Science, 2019.

Maduwanthi, S. D. T. and Marapana, R. A. U. J. (2019)b. Comparative Study on Aroma Volatiles, Organic Acids, and Sugars of Ambul Banana (Musa acuminata, AAB) Treated with Induced Ripening Agents. Journal of Food Quality, 2019.

Marriott, J. and Palmer, J. K. (1980). Bananas - physiology and biochemistry of storage and ripening for optimum quality. Critical Reviews in Food Science \& Nutrition, 13(1): 4188.

Maureen, C. O., Chisom, I. F., Esther, A. E., Ruffina, A. N. and Ann, M. O. (2016). A study of the effects of induced ripening on the proximate, biochemical and mineral compositions of Musa sapientum (Banana). International Journal of Food Science and Nutrition, 1(2): 15-20.

Ranaweera, S. J., Ampemohotti, A. A. L. T. and Arachchige, U. S. (2020). Banana ripening by smoking cabinet. International Journal of Scientific \& Technology Research, 9(3): 4395-4401.
Rose, R., Rose, C. L., Omi, S. K., Forry, K. R., Durall, D. M. and Bigg, W. L. (1991). Starch determination by perchloric acid vs enzymes: evaluating the accuracy and precision of six colorimetric methods. Journal of Agricultural and Food Chemistry, 39(1): 2-11.

Salunkhe, D. K. and Kadam, S. (Eds.). (1995). Handbook of fruit science and technology: production, composition, storage, and processing. CRC press.

Singh, B., Singh, J. P., Kaur, A. and Singh, N. (2016). Bioactive compounds in banana and their associated health benefits-A review. Food Chemistry, 206: 1-11.

Sogo-Temi, C. M., Idowu, O. A. and Idowu, E. (2014). Effect of biological and chemical ripening agents on the nutritional and metal composition of banana (Musa spp). Journal of Applied Sciences and Environmental Management, 18(2): 243-246.

Sonmezdag, A. S., Kelebek, H. and Selli, S. (2014). Comparison of the Aroma and Some Physicochemical Properties of $\mathrm{G}$ rand Naine (Musa acuminata) Banana as Influenced by Natural and Ethylene-Treated Ripening. Journal of Food Processing and Preservation, 38(5): 2137-2145.

Subbaiah, K. V., Jagadeesh, S. J., Thammaiah, N. and Chavan, M. L. (2013). Changes in physico-chemical and sensory characteristics of banana fruit cv. Grand Naine during ripening. Karnataka Journal of Agricultural Sciences, 26(1).

Von Loesecke, H. W. (1950). Bananas: Chemistry, Physiology, Technology. 